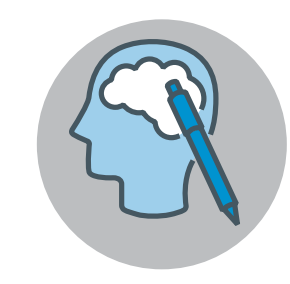

EDITORIAL

Renee Kiner \&

Kelly Safin

Millstein Library,

University of Pittsburgh

at Greensburg

\title{
Lessons Learned
}

1 s faculty librarians on a regional, undergraduate campus of a research university, with enrollment at around 1,400 students, we frequently attend faculty senate and other committee meetings. We have found that these meetings are a valuable way to connect with colleagues and their work. On several occasions, we heard them comment that they would appreciate wider recognition of their efforts inside and outside of the classroom. With these comments in mind, conversations started within the library about recognizing one aspect of this work-faculty scholarship-in some way.

The value of faculty recognition has been explored by researchers. In interviews and focus groups, Benito and Scott-Milligan (2018) found that achievements faculty consider important but under-celebrated included publication of a paper, conference presentations, external awards,

((Mapping out a plan early on, with time built in to address delays or surprises, is key to coordinating a successful event. /) participation in or organization of an event, and participation in or organization of a community activity . More formal recognition could enhance the motivation and engagement of faculty (Benito and Scott-Milligan 2018). Additionally, among full-

and part-time faculty, recognition within their division or institution can "foster a stronger sense of respect among faculty of all appointment types." (Eagan 2015, 475)

Realizing the need and importance of recognizing the scholarship and other work of faculty, we brainstormed ideas about organizing an event showcasing faculty scholarship and service. With publications being a focus, the library was a logical location. Another reason to host this event was its potential as an outreach opportunity. Several long-time library employees had left in recent years, a few within months of each other. The campus had experienced its share of personnel changes as well. This recognition event would boost outreach to faculty who might be new or unfamiliar with the services and liaison work of librarians.

We also consider this type of outreach an important way to help faculty recognize the value of librarians as partners in their work with students. Kelly (2019) explored the topic of faculty perceptions of librarian value, noting "faculty who felt positively about librarians in the first place, encouraged their students to work more frequently with librarians than faculty who held a less positive initial view of librarians" (232). Thus, this opportunity to host faculty in a positive setting would potentially raise awareness of library services, prompting faculty to recommend librarian consultations to their students.

\section{Bringing the Idea to Fruition}

Once we decided to begin planning a faculty recognition event, we realized that partnering with Academic Affairs would be beneficial, given this office's 
Campus Engagement: Faculty Recognition and the Library's Role, continued central role in faculty activity. We met with the Vice President of Academic Affairs (VPAA) a few times to discuss logistics such as the type of work highlighted, the means of sharing this work with the library, and the event date.

The VPAA advised us to focus on three areas that she considered representative of faculty's efforts: Publications, Presentations, and Community Service. The librarians added Grants, Stipends, and Awards as another area to highlight. The chairs of the campus's three academic divisions, comparable to other institutions' department heads, were the recommended sources for accomplishment information. The three chairs collected information from faculty for their annual reviews, which included publications and other achievements. The VPAA and librarians agreed that soliciting this information from the chairs would be most efficient.

Several factors influenced the decision to choose late September as the event time. This is typically a busy month on any college campus, but October and November have their own challenges with midterms, student activities, and the Thanksgiving holiday. Spring semester was ruled out almost immediately; we didn't want our event to compete with spring break or interfere with seniors' final project presentations, and in our area, spring brings with it the potential for inclement weather hampering commutes.

Once these details were settled, the bulk of planning fell to the librarians. Our focus moved to displaying the faculty achievements in the library. Displaying books and articles is straightforward, but how could presentations, service, grants, and awards be showcased? This was at the forefront of the event creation process.

Starting an annual event can be overwhelming, with small details popping up and, occasionally, morphing into bigger details, as we will show below. Mapping out a plan early on, with time built in to address delays or surprises, is key to coordinating a successful event. As this plan came together, it was clear that effectively collecting, compiling, and displaying each faculty accomplishment was essential. Addressing the most pressing need-collecting the information--we reached out to division chairs around the time that faculty were required to submit their reviews. We explained that we had the support of the VPAA in making our request. We provided a deadline that gave us ample time to put together the display without too much interference with our daily responsibilities.

In theory, receiving the information from division chairs would be the most efficient method for everyone involved. However, only two of the three division chairs submitted their faculty achievements. The third instead asked faculty in that division to submit information directly to the library. This was a snag we were not expecting, as it was unlikely faculty traveling for recreation or research during the summer would be online to respond.

Once the information from the two division chairs was received, reviewed, and grouped into categories, we formulated our display plans. Book publications would be displayed on a table along with articles, which we printed and organized in folders for each faculty member. For Community Service, Presentations, and Grants, Stipends, and Awards, information was printed alphabetically by last name on large posters-convenient because our library owns a poster printer. The posters were then framed and displayed on easels. This process sounds straightforward, but we did not anticipate how time-consuming it would be to format everything for consistency. Would we use professional titles? Would items be organized by faculty last name, division, or both? Adding to this was the occasional submission from faculty on their own behalf, incomplete citations requiring extra searching to locate, and a few instances where requests for journal articles from other libraries took longer 
than expected to be filled. We also set aside anything not yet published to be displayed the following year. During these preparations, we realized the amount of material might interfere with foot traffic to our busiest computer area, so we changed the layout for the materials and refreshments to better accommodate our patrons.

As an outreach tool, this event had staying power because we chose to continue displaying this material afterward. We placed the posters, books, and publications in the display case near the library entrance. Students, staff, and faculty entering or exiting the library could view what faculty had worked on the previous year.

What happened to the information from the third division? Only a few people responded, so this group was not well-represented at the event. A few faculty members who attended the event noticed this gap in representation. Many colleagues were aware that division chairs had been asked to provide the information, but those who were not were politely informed that the omission was not intentional on the librarians' part. Our second event had information from all three divisions, which also made the display a lot larger.

\section{Positive Outcomes}

Faculty impressions. Faculty seemed genuinely happy that the library hosted this informal networking event. They were able to view their colleagues' work while answering questions about their own achievements. Additionally, we overheard and took part in conversations about future projects and collaborations. Our goal was to draw in at least five faculty members, and about twelve attended. For these reasons, we considered our first event a success. At the second event one year later, attendance increased to about thirty faculty members.

Student impressions. The library was open during this event, and students were able to view the posters, browse publications, and talk with their instructors. Students also stopped and looked at the displays of faculty work after the event. Researchers have studied students' perceptions of faculty research and how it affects views of faculty overall. Based on responses of university students in the UK, Healey, Jordan, Pell, and Short (2010) found "the most positive facet of being taught by research-active staff was considered to be their enhanced enthusiasm and motivational abilities. [Students] tended to associate staff involvement in research with up-to-date knowledge. . ." (242). Students attending the event or looking at the materials displayed afterward had the opportunity to see how their professors contributed to their fields and continued to learn through their research.

Faculty achievement is not limited to publications and presentations, however. Student knowledge of faculty involvement in the community can also influence their view of instructors. This is one reason why the categories of Service and Grants, Stipends, and Awards are part of this event. O'Brien and Pizmony-Levy (2016) found that some students viewed faculty participation in community groups as evidence of a personal commitment and understanding of social issues. Faculty "credibility is boosted by their combined academic expertise and personal commitment to social action" (262).

\section{Discussion}

Increase in faculty attendance. The increase in faculty attendance between the first and second events could be attributed to two factors: a new campus president and advertising-especially word-of-mouth promotion. The second event was held during the new campus president's first fall semester. He was very interested in the event, agreeing to provide brief remarks. This was noted 
Campus Engagement: Faculty Recognition and the Library's Role, continued on the invitation, and a few attendees commented that the opportunity to greet him was one reason they stopped in. The president also suggested a more attention-getting name for the event, so it became the Celebration of Faculty Scholarship and Service.

The librarians also increased their marketing efforts leading up to the second event. Both years, the library director emailed faculty a postcard invitation.

Prior to the second event, we also intentionally mentioned the event in conversations with faculty as much as possible. Each librarian also encouraged faculty in their liaison areas to attend with an emailed reminder. Word of mouth from those who attended the first year also helped with attendance, along with the additional promotion around campus.

Outreach and engagement. Drawing more faculty members into the library is beneficial, but we tried to foster even more engagement during the event and beyond. During both events, we had informal conversations with faculty about instruction, research consultations, course reserves, and library materials. While discussing their work and classes, we were able to show how the library could help them. Some attendees also chimed in to share their positive experiences requesting materials via ILL for their research.

\section{Recommendations}

Start small. Set manageable expectations and be prepared to learn from missteps. We did not expect a huge turnout during our first year; our main goal was to learn how to put the event together and what it would entail. We were fortunate to have that opportunity. We also learned that greater buy-in from division chairs might be achieved by meeting with them directly. To that end, we attended a meeting of the VPAA and the division chairs before the second event, so that everyone heard the same message about their role in making the effort a success.

Get involvement from other areas on campus. When trying something new, partnering with another department or group can help with logistics and outreach. The input of the VPAA helped us better understand the process by which faculty shared their achievements with their division chairs. Additionally, the President's participation in the second event generated interest. We also had the support of our library staff colleagues, who helped with poster printing and other setup details. Finally, Academic Affairs also shared refreshment costs.

Provide refreshments. If the event is in person, consider offering refreshments. We had light lunch offerings, such as vegetable trays, finger sandwiches, and desserts. We held the event over the lunch hour, so offering food was incentive to attend.

Choose an appealing location. Our library is a welcoming space, with natural light and views of the campus. However, because of the open design of the building, events are not typically held there during operating hours. Because this event was relatively passive, with minimal noise beyond quiet chatter, it worked well at that point in the semester. An event with lots of speeches and applause, or held around midterms or finals, might have been considered a disruption.

Collect and review feedback. Evaluating the success of an event can be as simple as asking participants to informally share their opinions, or creating a survey for them to complete anonymously. After the first event, a survey sent to faculty found that many wanted to attend but could not due to illness or other obligations. With that in mind, we did increase promotion to try to get the event on calendars earlier. We did not conduct a survey for the second event, but the campus administration offered specific feedback immediately afterward: they 
requested that each division chair give formal remarks about their colleagues' work, in addition to the President's welcome. We will be incorporating this brief programmatic aspect into future events.

\section{Conclusion}

We believe these events were successful in accomplishing our original goals: faculty outreach and recognition of their work. The faculty that attended felt the campus recognized their past year's achievements, and viewed the library favorably for creating and hosting the event. Starting a low-stakes event like this one benefitted both faculty and librarians. At this relaxed networking opportunity, we were able to connect with faculty members less familiar with the library, including new faculty. We also continued building rapport with faculty who already referred students to us. After these events, we can anecdotally report that we've had more inquiries from instructors about library services, including instruction sessions and consultations.

Although COVID-19 restrictions will change the format of the third event, planning is underway to collect information from division chairs and compile posters and documents for some type of recognition during the fall 2020 semester. The format may be completely virtual, with bibliographies linked to faculty work available online. If the library is open with limitations, we may develop a companion web page that includes recorded remarks from the President and division chairs, along with a physical display of materials, instead of a gathering. In any case, we plan to use the groundwork in place to create another event and display of faculty scholarship and service.

\section{References}

Benito, Águeda and Fionna Scott-Milligan. 2018. "Hearing the Voice of Faculty: Global Recommendations for Faculty Recognition in Higher Education Institutions." Higher Learning Research Communications 8 (2): 1-8. https://doi.org/10.18870/hlrc.v8i2.433.

Eagan, M. Kevin, Jr., Audrey J. Jaeger, and Ashley Grantham. 2015. “Supporting the Academic Majority: Policies and Practices Related to Part-Time Faculty's Job Satisfaction." The Journal of Higher Education 86 (3): 448483. https://doi.org/10.1353/ihe.2015.0012.

Healey, Mick, Fiona Jordan, Barney Pell, and Chris Short. 2010. "The ResearchTeaching Nexus: A Case Study of Students' Awareness, Experiences and Perceptions of Research." Innovations in Education \& Teaching International 47 (2): 235-46. https: / doi.org/10.1080/14703291003718968.

Kelly, Savannah L. 2019. “Faculty Perceptions of Librarian Value: The Moderating Relationship between Librarian Contact, Course Goals, and Students' Research Skills." The Journal of Academic Librarianship 45 (3): 228-233. https://doi.org/10.1016/j.acalib.2019.03.003.

O’Brien, Timothy L., and Oren Pizmony-Levy. 2016. “Going Public, Gaining Credibility: Student Perceptions of Publicly Engaged

Scholars." Sociological Perspectives 59 (2): 246-69. https://doi.org/10.1177/0731121415586634.

\section{Author Details}

Renee Kiner, Public Services Librarian: reneekiner@pitt.edu Kelly Safin, Reference/Public Services Librarian: kelly.safin@pitt.edu 